\title{
REFLEXIÓN SOBRE LA PRIMAVERA ÁRABE Y LAS PROBLEMÁTICAS DE LA SOCIEDAD ÁRABE
}

\author{
Ali Hadjar Kherfane \\ Universidad de Sevilla
}

No hay duda de que la llamada "primavera árabe" es un acontecimiento sin igual en la historia contemporánea de los árabes, pues ha creado en este pueblo una conciencia colectiva sobre su capacidad de cambiar. El pueblo ya no es una comparsa en el decorado del líder visionario. Ya no es un "fenómeno de voces" que se sacrifican verbalmente a su guía en cuerpo y alma. Esta vez las masas están en la calle para gritar con alta voz al presidente antes glorificado: ¡Márchate!

Pero ésta no es la primera rebelión en la historia contemporánea del mundo árabe. Es el resultado de la larga y difícil lucha de una sociedad que durante mucho tiempo ha tenido a la tiranía como único destino, como la describió en 1900 el pensador sirio 'Abd al-Rahmān al-Kawakibi en su famosa obra Caracteres del despotismo y lucha contra la esclavitud (Tabä'i' al-istibdäd wamașāri al-istibajd). La historia árabe ha conocido muchas rebeliones contra los regímenes árabes que van desde las movilizaciones pacificas en las plazas y las marchas desde las mezquitas hasta los movimientos violentos y armados.

Por ejemplo, en Egipto el bloqueo político y la instauración de un régimen militar a partir de 1952 con la revolución de los Oficiales Libres, y sobre todo después de la derrota de 1967 ante Israel, habían contribuido al descontento generalizado, llevando a la aparición de grupos armados y al asesinato del presidente Anwar al-Sadat en 1980 por el grupo islámico "al-Yamáa al-Islamiya" por haber firmado los Acuerdos de Camp David con Israel en 1978; y durante los últimos años ha habido mu- 
chas movilizaciones de la sociedad civil egipcia, como el movimiento de "Kifaya" o el del "6 de Abril", para contestar al poder del Presidente Mubarak y su clan.

En Túnez, tuvo lugar el levantamiento de Redeyef (Ridiyif) en 2008; a pesar del limitado espacio geográfico de este levantamiento, circunscrito a una determinada región del país, la intensidad de la movilización y el contenido de las reivindicaciones políticas y sociales de las masas que se rebelaron contra la injusticia y la marginación desenmascararon la realidad política y la falsa imagen del régimen; desgraciadamente, el oportunismo político y la manipulación ideológica de esta revuelta permitieron al régimen reprimirla de forma sangrienta.

Y en Argelia la voluntad popular fue secuestrada a principios de los años noventa por el régimen argelino, tras las elecciones más trasparentes que había habido en la historia política del país y tal vez en la historia política contemporánea de todo el mundo árabe, dando lugar a protestas en toda Argelia, con manifestaciones en las plazas principales y con marchas tras cada oración del viernes; se produjo una movilización política de toda la oposición contra el régimen; esa acción política no fue sólo obra de la corriente islamista, sino que participó todo el espectro político: el izquierdista Partido de los Trabajadores (PTT), el Frente Islámico de Salvación (FIS), el Frente de Liberación Nacional (FLN) que había liderado la rebelión contra Francia durante la guerra de independencia, las Fuerzas Socialistas (FS) quien era el partido más influyente en el área de la Kabilya y de tendencia laica..., es decir, las formaciones políticas más representativas de la población. Por otro lado, todos los ámbitos de la sociedad estaban presentes en esa movilización: estudiantes, trabajadores y mujeres; la presencia de la mujer fue muy significativa, pues era la primera vez desde la guerra de independencia en que había tantas mujeres en el centro del acontecimiento. La participación femenina en las marchas era im- 
portante. Frente a esta movilización popular, el régimen ejerció una feroz represión, por lo que aparecieron grupos armados y se desató un ciclo terrible de violencia, de consecuencias dramáticas, que causó más de 150.000 víctimas.

Estos acontecimientos fueron considerados, por la llamada comunidad internacional, como un problema interno, y nadie habló de una "primavera argelina" o de una revuelta por la dignidad. La victoria de los islamistas del Frente Islámico de Salvación (FIS) había sido considerada por los medios mundiales como un peligro inminente y una amenaza para la democracia y los derechos humanos. Las grandes potencias no trataron de encontrar una solución pacífica para la crisis argelina. Los medios se centraron en el aspecto de la seguridad. Estos acontecimientos demostraron la hipocresía política de las grandes potencias, que obraron de acuerdo con sus intereses, y no con los principios que decían defender.

Tampoco se puede negar que la oposición islamista cometió un grave error estratégico, recurriendo a las armas contra al régimen. Lo que hoy vemos en Libia, Siria e Iraq demuestra que la preservación de las instituciones estatales es más importante que cualquier otra consideración. Pero, por otro lado, no se pueden justificar en ningún caso los abusos cometidos por el régimen en relación a los derechos humanos.

Los acontecimientos de Argelia se produjeron al mismo tiempo que la caída del Muro de Berlín y las olas "democráticas" en los países del Este. Pero el cinismo político internacional consideró esos acontecimientos argelinos como una cuestión interna, mientras consideraba los que se producían en la Europa del Este como un problema que atañía a todo el mundo libre.

Entonces, ¿cuál es la diferencia entre lo que sucedió en Argelia, por ejemplo, y lo que ha sucedido en Túnez, Egipto o Libia? ¿Y por qué las protestas de Bahrein han sido ocultadas por 
los medios internacionales a pesar de que sus reivindicaciones eran iguales a las de los otros pueblos árabes?

$\mathrm{El}$ factor tiempo es importante en la interpretación de los acontecimientos. En los años noventa, la OTAN inició su expansión hacia el este como consecuencia de la caída del comunismo, y no era conveniente para el orden mundial introducir cambios estratégicos en la frontera sur de la OTAN. Pero las cosas han cambiado tras las guerras en Afganistán e Iraq, la grave crisis económica y el relativo aislamiento de los Estados Unidos.

Otro factor decisivo que hace que lo que está sucediendo en el mundo árabe sea diferente a los acontecimientos de Argelia es, por ejemplo, el poder de los medios de comunicación que lo acompañan y, sobre todo, el uso político que se hace de los propios acontecimientos. Los medios de comunicación han jugado un papel fundamental - en particular el canal qatarí al-Yazira - para dar apoyo al movimiento de protesta que se extendió por el mundo árabe en 2011, algo que no hicieron con el de Bahrein, al que dieron otro significado político: cualquier levantamiento popular en los Estados del Golfo es contra la legitimidad institucional - como es el caso de Bahrein-, pero el mismo caso se convierte en una revolución por la dignidad en los otros ámbitos geográficos del mundo árabe.

El papel de Arabia Saudí y Qatar ha estado claro en el caso de Libia: ambos países participaron activamente en el derrocamiento del régimen de Gadafi, mientras que Arabia Saudí enviaba su ejército para reprimir la sublevación de la población de Bahrein y proteger al régimen de Salih. Parece paradójico que países que aplican a los trabajadores extranjeros un sistema casi feudal estén tras las movilizaciones que reclaman libertad y justicia social, aunque la adhesión de estos países al sistema neoliberal explica en cierta medida esta contradicción.

Sin embargo, toda esta situación requiere que nos hagamos algunas preguntas a la luz de nuestra lectura de la historia de los 
acontecimientos para darles un sentido y ponerlos en su justo contexto histórico.

\section{LA GRAN ILUSIÓN}

Siguiendo los acontecimientos de la "primavera árabe" se halla una cierta similitud - geográfica y temporal - con la ola de movimientos de liberación nacional que conocieron la mayoría de los países árabes y africanos en los años cincuenta. Fueron movimientos de liberación legítimos, pero los hechos sucesivos nos revelan que al final sólo habían producido una "gran ilusión". De hecho, las grandes potencias habían sustituido la vieja y costosa actividad de colonización por un neocolonialismo que no les costaba nada a los colonizadores.

Aplicando la misma lógica, nadie puede poner en discusión la legitimidad de los movimientos que han sacudido gran parte del mundo árabe para reclamar su dignidad y sus derechos, pero era ingenuo creer que esto ocurriría sin que las grandes potencias tratasen de controlar las situaciones, dirigiendo el desarrollo de los acontecimientos hacia sus intereses. La región árabe es un área de valor estratégico vital para los principales actores del mundo, y no permitirán dejar que las cosas evolucionen en un sentido opuesto a sus intereses estratégicos.

El pensador marroquí Idris Hani, en su artículo "Reflexiones sobre la marcha de las revoluciones árabes" (Ta'ammulat hawla masirat al-țawrat al-'arabiya), publicado en el n. 74 de la revista al-Kalima, en 2012, nos habla de esa "gran ilusión”. Por otro lado, el escritor egipcio Fahmi Huwaydi, en su artículo "Sobre el secuestro de la primavera árabe” ('An ijtitaf al-rabi'al-'arabi) ${ }^{1}$, publicado en 2011 en el periódico qatarí al-Sarq, se muestra preocupado por el riesgo de que la "primavera árabe" sea sim-

${ }^{1}$ Fahmi Huwaydi, "Sobre el secuestro de la primavera árabe" ('An ijtitaf al-rabi' al-'arabi), Al-Sarq, 27 de septiembre, 2011.

http://fahmyhoweidy.blogspot.com/2011/09/blog-post 27.html 
plemente secuestrada. Y Robert Fisk, en su artículo "La brutal verdad sobre Túnez" (The brutal truth about Tunisia) ${ }^{2}$, publicado en 2012 en el periódico inglés The Independent, no ve el final de la dictadura en un mundo árabe corrupto, cruel y humillado.

Estos análisis pueden ser correctos en su totalidad o en parte, pero es curioso que el papel del mundo árabe en todo lo que pasa sea tan marginal y secundario. Por tanto, la cuestión clave no es lo que otros quieren de los árabes, sino lo que los árabes quieren de sí mismos.

El problema del mundo árabe no está sólo en los regímenes autoritarios. China no es un oasis de democracia en todo caso, pero se está moviendo rápidamente para convertirse en el país más poderoso del mundo, y Rusia es un actor muy influyente en la escena internacional a pesar de todas sus carencias "democráticas".

$\mathrm{E} 1$ problema del mundo árabe es fundamentalmente un problema estructural. A pesar del impacto positivo que dejó la llamada "primavera árabe", especialmente en el aspecto psicológico y cultural, las dificultades que están viviendo esos países han demostrado claramente que el problema del mundo árabe es algo más que un mero problema de régimen. Pensar que se puede resolver el problema "árabe" con revoluciones de primavera es de un optimismo exagerado.

La libertad, la justicia, la igualdad, la democracia, los derechos humanos y el estado de derecho no son conceptos abstractos. La democracia no tiene un significado retórico, sino que es un proceso complejo basado en hechos y cifras concretas. Es el resultado de un profundo cambio estructural en la sociedad humana, al transformarse una sociedad agraria en una sociedad in-

${ }^{2}$ Robert Fisk, "La brutal verdad sobre Túnez" (The brutal truth about Tunisia), The Independent, 17 de enero, 2011.

http://www.independent.co.uk/voices/commentators/fisk/the-brutaltruth-about-tunisia-2186287.htm 
dustrial, y se vincula principalmente a la organización de la sociedad y a la creación de riqueza y su distribución.

La revolución industrial del siglo XVIII cambió la estructura social y política de la sociedad europea de manera radical. Una de sus consecuencias más importantes fue el desarrollo del sindicalismo, que fue el resultado de una dura lucha de la clase obrera para lograr sus derechos y, por lo tanto, para acabar con el sistema feudal, creando una especie de equilibrio entre capitalistas y trabajadores, basado en la necesidad que tenía la industria de una especial competencia profesional de los trabajadores, mejorando así las condiciones contractuales de éstos.

Otra de las consecuencias sociales de la revolución industrial que surgió en Europa fue la sustitución de las clases sociales del antiguo régimen - la nobleza y el clero- por nuevas clases sociales - la burguesía y la clase obrera- De este cambio surgió el principio de igualdad de oportunidades entre los diferentes estratos de la sociedad. El desarrollo industrial redujo en gran medida las diferencias étnicas o religiosas, no necesariamente por un principio moral, sino por un principio puramente práctico y funcional. En la sociedad industrial, la competitividad, el rendimiento de la fuerza de trabajo y las innovaciones técnicas son los valores más considerados, con independencia de la raza, el sexo y la religión. También el desarrollo del transporte, por ejemplo, ayudó a erradicar el aislamiento mental, contribuyendo al acercamiento entre regiones y a la mezcla de pueblos y razas - aquí es útil recordar que la marcha por los derechos civiles en Estados Unidos comenzó en un autobús-; y una línea ferroviaria que conecta las regiones de un país es más útil para la unidad nacional que la proclamada en retóricos discursos políticos.

El acceso del mundo árabe a la era industrial es una condición necesaria para lograr su liberación, no sólo en términos 
económicos, sino también en el sentido político y social, y podría contribuir a la solución de sus más grandes problemáticas: el problema de la identidad y el proyecto de sociedad así como el problema de la creación de riqueza y su distribución.

EL PROBLEMA DE LA IDENTIDAD Y EL PROYECTO DE SOCIEDAD

Tenemos que precisar que a pesar de que la historia del mundo árabe coincide a partir de un cierto momento con la historia del Islam, la historia de los árabes es más antigua que la aparición del Islam, que la mayoría de musulmanes no son árabes y que existen también árabes cristianos.

El mundo musulmán, incluido el mundo árabe, fue durante muchos siglos un actor principal de la historia universal, pero al mismo tiempo vivió graves crisis que lo marcaron profundamente. A pesar de que el Islam había creado una gran cohesión social, superando por cierto periodo el modelo tribal tradicional de la sociedad árabe, el estado árabe se convirtió al poco tiempo en el modelo de estado que Ibn Jaldun definió como "alianza entre una doctrina religiosa y un núcleo tribal".

Algunas de las causas fueron ideológicas, como el surgimiento de diferentes bloques religiosos - la Sunna y Chíaque a su vez se escindieron sucesivamente en otros subgrupos: los jariyíes en el bloque sunní y los fatimíes o los duodecimanos en el bloque chií. Otras causas fueron de naturaleza étnica, como el conflicto entre los árabes y las otras etnias que se habían convertido al Islam: se asiste al surgimiento, por ejemplo, de la šu'ubiya - movimiento del Islam primitivo que rechazaba la superioridad étnica de los árabes- en el Oriente islámico, y al conflicto entre los árabes y los bereberes en el Occidente islámico. Todo esto se debió al amplio espacio geográfico del estado 
islámico y a la multiplicidad de etnias que se sometieron a la autoridad de su Califato.

Bajo el Califato islámico surgió una civilización similar en fuerza y prosperidad a la civilización china; pero, a diferencia de la civilización china — que se mantuvo como una civilización interna y se limitó a una región de Asia y a una sola raza-, la civilización del Islam fue una civilización universal, que incluía a una gran variedad de grupos étnicos ${ }^{3}$.

A pesar de la prosperidad y el aspecto urbanizado de muchas ciudades islámicas, como Damasco, Bagdad, Córdoba, Sevilla, Granada, Fez o Tlemecén, el aspecto beduino ha sido siempre visible en la sociedad árabe. Y basta consultar su literatura para darse cuenta de la presencia del campo en la sociedad y la cultura árabes. Este contraste ha creado también una diferenciación social significativa:

La civilización arabo-islámica de la Edad Media difería en ciertos aspectos fundamentales del mundo feudal europeo, lo cual parece haber influido a más largo plazo en su distinto destino. Era una civilización en la que se articulaban una organización tribal, un tanto "primitiva", enclavada sobre todo en el campo, con unos aparatos estatales asentados en las ciudades y que peleaban incansablemente por someter a este mundo tribal y rural, siempre levantisco, tratando de extraerle los tributos que necesitaban para mantenerse en funcionamiento (Amin, 1976: 11-30; Ayubi, 1996: 83-131). Frente al arcaísmo social del campo, el mundo urbano sometido al poder estatal cobijó durante siglos una brillante civilización, cuyas bases materiales eran, sin embargo, un tanto endebles. Al estar desconectado parcialmente de su periferia rural, dependía en buena medida del comercio ca-

${ }^{3}$ Cf. Jacques Brasseul, "La decadencia del mundo musulmán a partir de la Edad Media: una síntesis de las explicaciones" (Le déclin du monde musulman a partir du Moyen Âge: une revue des explications). Revue Région et Développement, 2004, núm. 19, pp.19-54. 
ravanero, siempre vulnerable a los vaivenes de las luchas políticas; de ahí que la continuidad de los flujos mercantiles nunca estuviese garantizada. Esta dependencia frente al exterior acentuaba además la separación entre el campo y la ciudad y entre las tribus y el Estado. La sociedad sufría un acusado fraccionamiento interno, tanto horizontal, entre sus distintas regiones, como vertical, entre el conjunto de la población y la reducida élite que controlaba el Estado. El resultado final fueron unas instituciones estatales carentes de reconocimiento social, y obligadas a imponerse siempre por medio de la fuerza. El Estado era, en el sentir de las gentes y en la visión de los intelectuales, una realidad profundamente ajena, un poder exterior y hostil al que no quedaba otro remedio que soportar. Este sentimiento de externalidad ha pervivido hasta el día de hoy (Ayubi, 1996: 44-49; Laroui, 1998: 87-125) y quizá constituya [...] una de las razones del moderno auge de los movimientos islamistas (Ghalioun, 2004: 259-290) ${ }^{4}$.

Cualquiera que visite las ciudades del mundo árabe -El Cairo, Túnez, Argel o Casablanca- puede observar cómo los signos del campo son muy evidentes en el centro mismo de ciudades.

Toda esta diversidad étnica, ideológica y social ha contribuido a dificultar el hallazgo de factores unificadores de la sociedad. Esta diversidad podría explicar el surgimiento de diferentes escuelas de jurisprudencia, de acuerdo con las tradiciones de las diferentes comunidades. Pero, a pesar de toda esta diversidad, la legislación ha estado basada principalmente en la ley islámica, con diferencias en las ramas y no en las raíces, teniendo en consideración las costumbres y las tradiciones de las diferentes regiones. En el aspecto cultural, el componente árabe era

${ }^{4}$ Juan Ignacio Castién Maestro, "Problemas de la modernización en el mundo árabe contemporáneo", en Boletín de Información, Ministerio de Defensa, 2009, núm. 311, p. 82. 
dominante, debido a que el idioma del Corán era el idioma de los árabes.

Esa frágil cohesión duró varios siglos, pero con la llegada del colonialismo la situación cambió radicalmente. El mundo árabe, que se descubrió a sí mismo y se despertó de un largo letargo, sufrió una gran conmoción. El nuevo invasor no se impuso sólo por la fuerza de sus armas y sus ejércitos, sino que esta vez se impuso también por su estilo de vida y su desarrollo económico y tecnológico. Era un estilo completamente diferente, que introducía un nuevo modelo cultural y un nuevo código legislativo.

En Egipto encontramos, por ejemplo, una ciudad como la Isma'iliya de los años veinte, una ciudad completamente diferente de lo que eran las ciudades egipcias de la época. Ismáiliya no era sólo la sede de la Compañía del Canal de Suez, sino también una ciudad hecha de dos ciudades, una para los europeos y otra para los egipcios, con sus respectivas tradiciones, sus valores, sus costumbres y sus niveles de bienestar ${ }^{5}$.

Lo mismo ocurrió en otras ciudades en el mundo árabe, como Argel, que se convirtió en una parte integrante de Francia. $\mathrm{El}$ conflicto político y cultural que surgió después de la independencia creó una evidente contradicción en la sociedad árabe. El problema de identidad que existía entre colonizador y colonizado antes de la independencia se convirtió en conflicto entre los componentes de la propia sociedad. El problema de la identidad en los países del Magreb, por ejemplo, se produjo en términos culturales entre los defensores de la francofonía y los defensores de la arabización. Así la lengua, en lugar de ser un in-

${ }^{5}$ Basir Musà Nafa', "Retroceso del discurso identitario en la corriente islamista" (Tarayu' jitab al-buwiya ladà l-tiyar al-islami), Al-Quds al-Arabi, 3 de mayo, 2012. 
strumento de conocimiento, se convirtió en instrumento de lucha ideológica y en herramienta para adquirir poder. Esto explica por qué la lengua francesa todavía mantiene su posición privilegiada en la administración y en el sistema educativo. Esta "polarización" ha creado una brecha entre la gran mayoría de la población arabófona y la minoría francófona que durante mucho tiempo ha monopolizado el poder en la política y la economía.

Durante la Guerra Fría al conflicto cultural se sobrepuso otro conflicto, de naturaleza ideológico-política, entre "progresistas "y "reaccionarios", con una falsa percepción de la modernidad y la autenticidad histórica y con un impacto desastroso sobre el desarrollo y sobre los métodos para solucionar los verdaderos problemas de la sociedad. Probablemente la causa palestina ilustra cómo este conflicto ideológico ha afectado a la lucha justa y heroica del pueblo palestino.

Este clima conflictivo produjo una esquizofrenia en la sociedad. La divergencia entre los diferentes estratos de la sociedad no se limitó sólo a la percepción de algunos aspectos de la economía y la política, sino que afectó a casi todos los aspectos de la vida. Así se puso en el centro del debate la comida y bebida de la gente, el arte, el trabajo de la mujer y su vestimenta, la legislación y las finanzas, el sistema bancario, los fines de semana y la ley de la familia. La divergencia no se limitó a opiniones políticas o económicas, sino que se convirtió en una divergencia sobre el proyecto de la propia sociedad.

Los resultados de las elecciones presidenciales en Egipto de 2012 mostraron el grado de divergencia sobre el proyecto de sociedad de los egipcios. A pesar de que el pueblo egipcio se había levantado contra el viejo régimen, las elecciones pusieron en riesgo que llegara a presidente un representante de ese mismo régimen. El debate en las elecciones egipcias no se había centrado en cómo resolver los problemas cotidianos de los egipcios, 
sino que era un debate puramente ideológico, relacionado con proyectos de sociedad casi contradictorios.

En ausencia de instituciones democráticas, la confrontación ideológica se ha convertido en confrontación entre los componentes de la sociedad y ha tomado un carácter violento. $\mathrm{Y}$ así han surgido grupos armados durante la historia reciente de casi todos los países árabes: Egipto, Líbano, Argelia, Libia, Siria, Marruecos, Yemen, etc. Se ha intensificado el conflicto entre quien se autoproclama guardián de los valores de la nación y de su religión, y quien se ve como portador de la modernidad, capaz de sacar al pueblo de la oscuridad hacia la luz. Pero, de hecho, la sociedad no se ha movido hacia adelante con ninguna de estas dos opciones.

Los islamistas se identificaron como los tutores de las personas y los dueños de la verdad absoluta; con una visión paranoica, han convertido la civilización islámica en la cima de las civilizaciones; y, leyendo algunos de sus artículos y discursos, se encuentra la misma visión de algunos escritos occidentales convencidos de la centralidad de la civilización occidental y su superioridad sobre las demás; y ambos casos reflejan un pensamiento estéril y un análisis superficial.

Y la mayor parte de los que se autodefinían como modernistas tenían una concepción completamente distorsionada de la sociedad. Vieron en la negación de su identidad histórica y en la total adaptación al modelo occidental el único remedio para el subdesarrollo del mundo árabe, hasta el punto de que algunos "modernistas" se dirigían a su población con la lengua del excolonizador, reproduciendo una pésima imagen de la antigua potencia colonial.

A pesar de lo que parece ser una contradicción entre los valores de los dos bloques, hay un denominador común: ambos tienen una estrecha relación con el poder establecido, debido a su naturaleza exclusivista: los islamistas del mundo árabe se han 
aliado con los países del Golfo y han utilizado esta alianza para la construcción de un poder político y financiero; y los que se describen como liberales e izquierdistas se han hecho con el poder con sistemas descritos como seculares y laicos, como ha sido el caso de Túnez, Iraq, Siria, Argelia y Egipto. Y esta relación con el poder está vinculada en gran medida al concepto de Estado que se produjo después de la independencia en el mundo árabe: el Estado no era concebido como una institución para organizar la sociedad, sino para controlarla e imponer un modelo ideológico particular.

Siguiendo esta lógica, algunos de los golpes de estado fueron apoyados por los llamados modernistas con el pretexto de frenar a los fundamentalistas, como ocurrió en Argelia en los años noventa del siglo pasado y ha ocurrido recientemente en Egipto, donde con el mismo pretexto estamos asistiendo a una extraña alianza entre la llamada sociedad civil y el ejército en Egipto contra los islamistas. Por otro lado, encontramos el escenario opuesto en algunos países del Golfo, donde se emitieron sentencias religiosas contra cualquier movimiento reformista con el pretexto de mantener la paz social, respetar el pacto con el gobernante y preservar la autenticidad de la sociedad.

Además de las divisiones por razones sociales y étnicas, religiosas y culturales, debidas al contexto histórico del estado en el Islam y al colonialismo, el Estado nacional que surgió después de la independencia produjo una nueva fisura institucional entre la institución del ejército y el resto de la sociedad. La institución militar se ha convertido en una institución independiente y ha formado lo que podemos considerar un Estado dentro del Estado, con unos privilegios económicos y sociales que los ponen fuera del control del propio Estado.

Ante todas estas divisiones en la sociedad, la fuerza se convirtió en el único instrumento para unificar la nación y someter a la sociedad al poder de las instituciones. Esto explica en parte 
el "fenómeno" de los golpes militares y la "estatalización" de la dictadura en el mundo árabe. Este puño de hierro ha producido una cierta estabilidad aparente, que podemos llamar "estabilidad crítica", y cada tentativa de romper esta estabilidad podría afectar a la propia existencia del Estado.

En ausencia de un proyecto estatal unificador, el proyecto de la "tribu" se convierte en el único proyecto posible, y el resultado inevitable es la "democracia importada" o la libre elección subjetiva. La historia de Oriente Medio nos muestra cómo el proyecto de la "tribu" ha ganado al proyecto de Estado en Líbano y en Iraq, cómo puede prevalecer también en Siria, cómo ha producido la escisión tribal en Sudán, Yemen y Libia, y cómo el conflicto ideológico en Egipto y Túnez podría convertirse en una violencia que podría destruir al propio Estado.

Esto nos invita a pensar que en el mundo árabe la relación entre dictadura y ausencia de proyecto de sociedad no es necesariamente una relación causal: el Líbano no cedió a la dictadura de Siria, pero fue incapaz de superar sus diferencias; el ahorcamiento de Saddam Husayn y la eliminación de su dictadura no pudieron evitar a los iraquíes la tragedia que viven a causa del sectarismo y la división; y lo mismo ocurre en Libia.

La ausencia de un proyecto de sociedad que supere la inercia ideológica y ponga el desarrollo económico y los derechos humanos en el centro de atención, respetando la personalidad histórica del pueblo árabe, sigue creando una fisura social difícilmente reparable.

La ausencia de este tipo de proyecto podría anular todo lo que se había esperado de la llamada "primavera árabe", como ya había anulado previamente todo que habíamos esperado de la independencia del colonialismo.

En un momento mágico en la historia árabe, esta "primavera árabe" fue capaz de superar la división de la sociedad y poner al individuo árabe en el centro del acontecimiento, al margen de 
su fe, de su raza y de su clase social. Hemos visto cómo todos los estratos de la sociedad estaban presentes: mujeres y hombres, trabajadores y estudiantes, intelectuales y simples ciudadanos, con una sola reivindicación: la dignidad. Por ejemplo, en Maydan al-Tahrir se reunieron musulmanes y coptos, mujeres con velo y sin velo, trabajadores y académicos, toda la sociedad egipcia sin distinción ideológica. Pero fue sólo un momento de ardiente emoción que empujó a las personas a vivir un hermoso sueño por un breve momento antes de chocar con la realidad, una realidad con todos sus hándicaps políticos, históricos, sociales y culturales.

Los acontecimientos que se han sucedido y la confrontación que aún se vive en los países que han vivido ese movimiento han demostrado que ese momento unificador no era más que un momento "psicológico", cuando las personas son guiadas por la emoción. La construcción de un proyecto unificador requiere la reconstrucción de la estructura intelectual y cultural de la propia sociedad. Necesita superar la "polarización" ideológica y crear un programa de desarrollo económico basado esencialmente en la industria y la innovación tecnológica, sin limitarse a una economía rentista y consumista, para resolver el problema crucial de la creación de la riqueza y su distribución en el mundo árabe.

EL PROBLEMA DE LA CREACIÓN DE RIQUEZA Y SU DISTRIBUCIÓN

En el interesante artículo ya aludido, Jacques Brasseul estudia las razones del fracaso del mundo islámico, y menciona una anécdota de gran significado, producida durante una entrevista de Napoleón Bonaparte, que acababa de llegar a Egipto, con los Ulemas del Azhar: 
Durante la conversación, el general Bonaparte dijo a los sheijs que los árabes habían cultivado las artes y las ciencias en los tiempos de los califas, pero que ahora vivían en la más profunda ignorancia y que ya no les quedaba nada de los conocimientos de sus antepasados. El sheij Sadat respondió que les quedaba el Corán, donde estaba todo el saber. Napoleón les preguntó si el Corán enseñaba a fabricar cañones. Todos los sheijs respondieron con una sola voz: síb.

En este artículo Brasseul trata de responder a la pregunta fundamental: ¿por qué el fracaso de los árabes? Entre los argumentos interesantes que avanza está la tesis de lo que él llama "la rueda y el camello", y menciona en este sentido a Richard Buillet y su libro The Camel and the Wheel. ${ }^{7}$ En el capitulo "La sociedad sin ruedas" ( $A$ Society without Wheels) aborda la cuestión de las comunidades que han desarrollado un complejo inconsciente contra la rueda, lo que explica por qué los camellos han sido el modo preferido de transporte respecto a la rueda en el mundo árabe y también explica la ausencia de artillería móvil en los ejércitos árabes del pasado. Buillet ve en el rechazo a la rueda una causa importante del subdesarrollo que conoce el mundo árabe y que ha afectado también al estilo de las ciudades en el mundo islámico de tal modo que la mayoría de las carreteras de las ciudades islámicas no permiten el desarrollo de medios de transporte con ruedas. La marginación de la rueda y de la ciencia mecánica en el mundo árabe ha retardado la aparición de la revolución industrial. Y según Tellier, también citado por Brasseul $^{8}$, el concepto de la mecánica estaba totalmente ausente de la mente de las personas que dependían de un camello.

\footnotetext{
${ }^{6}$ Brasseul, loc. cit., 2004, p. 20.

${ }^{7}$ Ibid., p. 40.

${ }^{8}$ Ibid., p. 40.
} 
Ibn Jaldún ya desarrollaba una tesis casi similar. En al-Muqaddima, en el capitulo titulado "Los árabes son los más alejados de la industria", escribió:

La razón es que [los árabes] son de costumbres más beduinas y están más lejos de la urbanización y de las técnicas que necesitan. Mientras tanto, los persas y los cristianos cercanos al mar tienen tradiciones más coherentes con la urbanización, no conocen los camellos, que ayudaron a los árabes a afrontar el desierto y la pobreza, ni hay arena en sus tierras?.

Ernest Mandel, en su Tratado de la economía marxista ${ }^{10}$, menciona que las civilizaciones islámicas y las civilizaciones india, china y japonesa fueron esencialmente agrícolas, y los avances en los métodos agrícolas ayudaron al crecimiento demográfico, lo que retardó por miles de años la introducción de técnicas mecánicas debido a la abundancia de mano de obra. Por otro lado, el uso de la energía hidroeléctrica para la producción de productos no-agrícolas fue la base del lento avance de la mecanización en Europa entre el siglo XIII y el siglo XVIII, lo que no sucedió en las civilizaciones de tipo agrario, dependientes principalmente de la fuerza muscular, además de los altos impuestos que se imponían a la producción industrial y artesanal.

Estos factores pueden ser algunas de las razones por las que se retrasó la aparición de la revolución industrial en el mundo árabe, a pesar del enorme progreso que había conocido la civilización islámica en diversos campos, como es el caso de la ciencia al que se refiere Brasseul. Y Albert Hourani, citado por

${ }^{9}$ Ibn Jaldún, al-Muqaddima, El Cairo, Dar al-'Ahd al-Yadid, 2007,p. 375.

${ }^{10}$ Ernest Mandel, Traité d'économie marxiste, París, Union Générale d'Éditions, 1962, vol. 1, p. 154. 
Brasseul ${ }^{11}$, vio el comienzo del declive del mundo musulmán del siglo XVIII en el advenimiento de la revolución industrial en Europa.

La revolución industrial produjo en Europa, y más tarde en el mundo industrializado, una revolución en los conceptos, en la estructura social y en los derechos políticos. Hubo una trasformación importante de la economía tradicional, basada en la agricultura, en una economía de producción mecánica de bienes manufacturados a gran escala. Esta trasformación causó un cambio de costumbres sociales y una creciente demanda de mano de obra, con una fuerte migración del campo a las ciudades, creando nuevas ciudades en la ubicación de las nuevas plantas de producción. Las innovaciones técnicas ayudaron a producir, primero, máquinas de vapor, y luego, motores eléctricos, que dieron un gran impulso al desarrollo industrial.

La revolución industrial tuvo un gran impacto en la organización del trabajo y en la tendencia hacia la especialización y la fabricación de productos con alto contenido tecnológico que necesitaban un alto nivel de cualificación profesional. El uso intensivo del capital en la producción industrial fue creando nuevas clases sociales, diferentes a las que se encontraban en la época feudal. De este modo surgió el proletariado, los trabajadores de las plantas industriales, y una nueva clase de capitalistas, los empresarios que poseían los medios de producción.

La industrialización introdujo nuevos conceptos y nuevos hábitos de vida en la gente, y se comenzó a hablar de crecimiento, consumo e inversión como medio para mejorar la posición social del individuo. Sin embargo, la revolución industrial ha tenido un gran impacto en el bajo poder adquisitivo de los trabajadores y en el deterioro de sus condiciones de trabajo, pero esto fue también la causa del nacimiento de los sindicatos y

${ }^{11}$ Brasseul, loc. cit., 2004, p. 24. 
los movimientos políticos reformistas para defender los derechos de los trabajadores y mejorar sus condiciones laborales.

La falta de signos de revolución industrial en el mundo árabe hasta ahora nos lleva a la cuestión fundamental: cómo crear riqueza en ausencia de una cultura industrial en el mundo árabe.

La sociedad árabe, hasta el final del dominio otomano y el comienzo del colonialismo europeo en el siglo XIX y principios del siglo XX, no era muy diferente del resto de las sociedades feudales anteriores a la revolución industrial. Pero el mundo árabe no conoció la revolución industrial que conoció Europa, y por lo tanto la sociedad árabe no conoció los importantes cambios en la estructura económica, social y política que conoció Europa.

Con la aparición del colonialismo en la región árabe en los siglos XIX y XX, que produjo la explotación de la riqueza del mundo árabe por las potencias coloniales y el sistema capitalista, el sistema productivo feudal se convirtió en un sistema industrial. El sistema capitalista en el mundo árabe durante la época colonial no fue el resultado de una revolución industrial local, sino de la extensión de la revolución industrial europea, que hizo de las colonias una fuente de materias primas y mano de obra barata - la clase trabajadora, en su mayoría analfabeta y sin competencias-, lo que no ayudó a la creación de un clima favorable al surgimiento del movimiento obrero para defender sus derechos, como en el caso en Europa, a diferencia de la clase obrera árabe que emigró a Europa, la cual formó el núcleo de los movimientos de liberación nacional.

Después de la independencia, se formó una nueva clase capitalista local, relacionada con el comercio de Estado, que hizo decir a Muhammad Hasanayn Haykal que no hay ningún capitalista en Egipto en el sentido convencional, sino capitalistas de 
Estado, y que esto se aplica a otros países árabes ${ }^{12}$. Este capitalismo comercial no se convirtió en capitalismo industrial, como en Europa, aunque también comenzó con la acumulación de riqueza debida a la actividad comercial y colonial, disfrutando al principio de la protección del Estado, que con el tiempo se convirtió en actividad industrial productiva. La actividad económica en el mundo árabe se limitó al comercio y, en particular, a la importación de productos de los antiguos países coloniales. Y esto ha aumentado la dependencia económica del exterior, limitando el ciclo económico a la intermediación y al consumo, pero faltando el elemento fundamental, que es la producción.

Las caravanas de comerciantes tuvieron gran importancia en la historia de los árabes. El mundo árabe ha vivido a lo largo de la historia con una mentalidad negociante, una mentalidad basada principalmente en la negociación y la audacia, como la describe Ibn Jaldun:

El comercio significa crecimiento del dinero a través de la compra de bienes y su venta a un precio más caro que el de compra, y esto necesita astucia, compromiso y especulación. El comerciante debe ser audaz, calculador y muy prudente, y necesita tener relaciones con el gobernante para defender sus intereses y conservarlos ${ }^{13}$.

Es curioso que las características mencionadas por Ibn Jaldun sigan siendo válidas en el mundo árabe hasta nuestros días. La alianza del poder y el dinero es algo practicado a gran escala en el mundo árabe. Esta alianza es necesaria en el mundo financiero en ausencia de un poder judicial independiente que pueda ser invocado en caso de litigio. Y esta práctica ha consolidado la

${ }^{12}$ Muhammad Hasanayn Haykal, "Experiencia de una vida" (Tayribat Hayah), al- Yazira, 2011.

${ }^{13}$ Ibn Jaldún, ob. cit., 2007, p. 368. 
injusticia e instaurado una corrupción rampante en todos los niveles, que ha sepultado la posibilidad de desarrollo, ya que ha ayudado a la propagación de una economía paralela fuera de las instituciones del Estado y no sujeta a ningún control. De este modo, la creación de riqueza - o la posesión de la riqueza- se convierte en una práctica de comisiones y clientelismo políticofinanciero, trasformando la política en una cuestión de interés personal, en lugar de ser una cuestión de interés público.

$\mathrm{El}$ ascenso social y la adquisición de la riqueza dependen de criterios muy diferentes a los estándares de conocimientos y competencias. Así encontramos personas aventureras y audaces, según la definición de Ibn Jaldún, que al ser capaces de establecer relaciones con personalidades influyentes en el dispositivo estatal se convierten en muy poco tiempo en figuras prominentes e influyentes de la sociedad. Y, como la política ha sido un instrumento para enriquecerse, se ha convertido en una mercancía. No es raro encontrar a miembros del Parlamento y a líderes de partidos políticos analfabetos que, gracias a sus relaciones y sus riquezas, han podido entrar en el mundo de la política por la puerta grande.

La economía en el mundo árabe depende esencialmente de los ingresos del petróleo, que es su única fuente de riqueza; y, como el sector del petróleo es propiedad del Estado, el capitalismo árabe depende enteramente del Estado, sin convertirse en una potencia económica independiente, como ocurre en Europa.

Esta interrelación entre la política y el capitalismo árabe se ha convertido en un poder de decisión que influye en las políticas y las estrategias del Estado y que controla el curso de la economía en general en sus países. Por lo tanto, esa interrelación no ha sido sólo un impedimento para el desarrollo económico y social, sino que también ha afectado a la política, causando un fraude importante en el proceso político al convertirse la políti- 
ca, como hemos visto, en el instrumento principal para adquirir riqueza.

Bajo este sistema no será posible el surgimiento de una clase obrera capaz de defender sus derechos contra los empleadores a causa de la ausencia de una producción industrial que requiera competencias que permitan a los trabajadores negociar para mejorar sus condiciones, por lo que no ha ayudado tampoco a desarrollar el principio de los derechos de los trabajadores, que es una condición esencial para instaurar una sociedad justa. Y los sindicatos no son más que una caricatura al servicio de los regímenes existentes, siendo a menudo una parte del conflicto ideológico en lugar de defender los derechos de los trabajadores.

La ausencia de una economía basada en una industria manufacturera, en las competencias profesionales y en las innovaciones científicas y las invenciones, que permita al individuo alcanzar el éxito en función de su eficiencia y su capacidad, ha creado una economía cerrada, dirigida por fuerzas ocultas compuestas por una alianza compleja de política, finanzas y medios de comunicación. Todo esto ha aumentado la conflictividad sectaria y la división tribal, en cuanto hay grupos étnicos que monopolizan algunos sectores comerciales, $y$ ha agravado la división de la sociedad.

A pesar de la existencia de algunas de estas características en otras economías, como en China, Turquía, Irán, Brasil o India, la clase política en estos países se niega a depender totalmente de las principales potencias mundiales, a diferencia de la clase política en el mundo árabe, que prefirió jugar el papel de mediador y agente político con las grandes potencias a fin de preservar sus intereses personales y familiares.

La existencia de estos problemas estructurales en la sociedad árabe hace difícil que la llamada "primavera árabe" sea suficiente para lograr un cambio fundamental en el mundo árabe. La de- 
mocracia no es, en última instancia, un conjunto de buenas intenciones y un concepto abstracto: es un mecanismo concreto para alcanzar el bienestar de las personas, crear riqueza y distribuirla de forma equitativa, garantizando los derechos de los trabajadores y la justicia social.

La industrialización es una condición necesaria, pero no suficiente, para establecer un Estado democrático y moderno, en el sentido de que puede haber países industriales sin ser democracias - como China o Rusia, por ejemplo-, pero no hay ningún país democrático fuera del grupo de los países industrializados. La mayoría de los países que no son industriales tienen una economía que se basa esencialmente en un modelo rentista, que depende de los recursos naturales, como el petróleo, como ocurre en los países del Golfo, Argelia, Iraq y Libia, o en un modelo asistencial, con una economía relacionada con las ayudas extranjeras, como es el caso de otros países árabes; y ambos casos no favorecen las condiciones para desarrollar la creatividad y la competitividad, que son condiciones necesarias para instaurar una democracia.

En definitiva la revolución tunecina, y después la egipcia, han dado una nueva alma a los pueblos árabes, pero lo verdaderamente interesante de estas revoluciones es su capacidad de provocar un cambio profundo en el pensamiento árabe contemporáneo.

Se ha hablado mucho de la dictadura en el mundo árabe y de la necesidad de instaurar un sistema democrático para poder iniciar la fase de fundación del Estado árabe moderno. Pero no pueden resumirse todo sus males en la dictadura, como algunos analistas tratan de hacer creer.

China no es un paraíso democrático, pero a la vez es la segunda potencia mundial. Bajo la dictadura del partido único, China ha sacado de la pobreza a más de 300 millones de chinos, y en las últimas seis décadas ha multiplicado por 30 el PIB 
del país. En el artículo "Sombras chinescas", de Francisco G. Basterra, publicado en El Pais en 2011, Deng ha declarado: "China ha superado ya económicamente a Japón y Alemania, y en 10 ó 15 años adelantara a EE.UU.”. Se ha creado una amplia clase media que aún soporta, a cambio de bienestar, la represión de las libertades. Singapur, Corea del Sur o Vietnam representan también otro ejemplo de países que están emergiendo como potencias regionales sin ser democracias. Otro ejemplo son los países del Este bajo el régimen comunista: encontramos países como la ex Yugoslavia o la ex Republica Checa que producen en esta época, sea en el campo industrial o en el campo cultural, más que todos los países árabes juntos.

Pero la democracia es sobre todo una lucha de los trabajadores en el ambiente de trabajo, donde "la cadena de montaje" en la fábrica representa un símbolo de esa lucha. "La cadena de montaje" es un elemento fundamental para cambiar la mentalidad, al cambiar la relación "hombre/tiempo" y "hombre/capital". En una sociedad donde toda la economía se basa en la renta se crean las mismas condiciones de la sociedad feudal. En una economía no desarrollada y que no exige una cualificación especifica a los trabajadores no se dan las condiciones que crean el equilibrio entre el capital y los trabajadores para que éstos puedan contratar sus condiciones de trabajo y sus derechos a cambio de prestaciones específicas y cualificadas.

La falta de industrialización, como la verdadera creadora de la riqueza, hace que la única alternativa para enriquecerse sea la política. En los países árabes, que poseen la renta petrolera, el hombre político se convierte en protector de una banda de pseudo-emprendedores que monopolizan cada actividad económica y mercantil. En los países pobres, la política es el medio para acaparar las ayudas internacionales. La política no es ya una gestión del Estado, sino la gestión de las cuestiones de inte- 
rés personal. Y sin industrialización no se pueden crear las condiciones para instaurar un sistema moderno y democrático.

\section{REFLEXIONES DEL PASADO}

Merece una cierta reflexión un aspecto muy curioso de la comunidad árabe, y más específicamente de la comunidad del Norte de África, que cuenta, por ejemplo, con más de tres millones de personas en Francia y más de un millón en España, pero no es capaz de crear una fuerza política y financiera para defender sus derechos. Es verdad que hay problemas de naturaleza socioeconómica, como la xenofobia y el paro, pero se puede transformar el "gueto" impuesto por las instituciones y la sociedad en un lugar de creatividad para disfrutar del potencial en el interior de la comunidad, y no en un lugar para encerrarse en la pasividad y la victimización.

La importancia de la revolución árabe consiste en su capacidad de cambiar la estructura de la sociedad árabe e instaurar una nueva relación entre el gobernante y el gobernado, y la creación de una nueva cohesión social basada en factores lo más comunes posible.

Después de vencer a 'Alī Ibn Abī Țālib en la batalla de Siffīn en el 657, Mu'āwiya fundó la dinastía omeya, sobre la base del principio de la monarquía absoluta, cambiando radicalmente el sistema político del Islam, el cual se fundaba en la libre elección. Desde este trágico acontecimiento en la historia del Islam, y a pesar de la gran civilización islámica y su contribución en el campo científico y humanístico, el mundo árabe vive en un estado de conflicto permanente desde el punto de vista político.

Tras la caída del Califato y la división del mundo árabe, la colonización reforzó este conflicto con la creación de fronteras geopolíticas muy heterogéneas desde el punto de vista religioso y étnico. Después de la pseudo-independencia, y dentro de la 
misma nación pseudo-independiente con su constitución ya muy conflictiva, se ha creado un equilibrio artificial que podemos llamar "equilibrio asimétrico". Equilibrio de fuerzas entre una clase minoritaria con un poder absoluto — debido a una alianza entre la política, las finanzas y la información, apoyada especialmente por las potencias mundiales y en particular por los ex colonizadores para conservar sus intereses geopolíticos y económicos - y una clase mayoritaria marginada que vive en condiciones de extrema pobreza.

Esta minoría es de carácter étnico, cuando el poder está en manos de una tribu - como los Tikriti en el Iraq de Saddam o los Qaddafa en la Libia de Gadafi-, en manos de una familia - como es el caso de las monarquías árabes-, o el poder es de carácter religioso - como la minoría alawí chií que detenta el poder en una Siria de mayoría sunní, o la minoría sunní en un Bahrein de mayoría chií-, o de carácter ideológico en que el poder lo con-trola una clase política pseudo-modernista - $\mathrm{CO}^{-}$ mo es el caso argelino, tunecino y egipcio-.

Cada tentativa de romper bruscamente este equilibrio podría causar el reforzamiento de la minoría en detrimento de la mayoría, como ocurrió en Argelia después de los acontecimientos de los años 90, la instauración de un poder populista, como en Sudán, o el caos total, como en Iraq y en Somalia.

Este equilibrio crítico necesita un proceso razonado de análisis y síntesis de la sociedad en sus elementos de base para formular un proyecto de sociedad, con un denominador común lo más amplio posible basado en una combinación de democracia y justicia social y sin la negación de la civilización islámica y la identidad árabe.

Por último, podemos reproducir fragmentos de varios artículos que publiqué en 1992 y que parecen estar aún de actualidad. Veinticinco años después, el mundo árabe sigue viviendo la misma problemática y la misma situación sociopolítica. En es- 
te mismo periodo de tiempo el mundo ha vivido el ascenso de nuevas potencias, como India, Brasil, Turquía y otras naciones, mientras el mundo árabe busca aún su camino. Estos artículos fueron publicados en el periódico argelino al-ŶYazäir al-Yawm durante la crisis política de los años 90 . El primero se titula "Nuestra sociedad: análisis y síntesis" (Muŷtama'u-na bayna lfakk wa-l-tarkib) y fue publicado el 13 de mayo de 1992:

Para que una cultura pueda sobrevivir debe someterse a dos procesos básicos: el análisis y la síntesis, en la medida que el proceso de análisis sea el resultado del poder de ideas renovadoras y óptimas, en la medida que el proceso de síntesis esté en línea con esas ideas en conformidad con los cambios irrevocables de la historia, y en la medida en que esta cultura tenga fuerza de apoyo y de atracción hacia el centro de la civilización.

El proceso de análisis se parece de algún modo a una sacudida eléctrica que devuelve la conciencia al pueblo que ha perdido esa conciencia y su capacidad para moverse. Sin estas sacudidas continuas y alternativas, la humanidad no habría podido dar los enormes saltos en su largo camino ni habría logrado el gran cambio de construir la sociedad humana social.

Este proceso de análisis es básico y necesario para llevar la idea meramente abstracta al mundo de la realidad palpable, con todo el sufrimiento y la dificultad que entraña lograr su reacción.

Con esta difícil y dura transformación, el Islam pudo realizar una revolución social única en la sociedad beduina, para sacarla - como expresa el Corán- de las tinieblas a la luz. Y, si leemos la descripción del Sagrado Corán de esta operación transformadora, podemos darnos cuenta de la fuerza de atracción y de la cantidad de energía liberada para hacer salir a la comunidad preislámica de la órbita de su estéril ignorancia espiritual hacia su fértil órbita culta, e imaginarnos la 
fuerza necesaria para salvar a quien está al borde de un abismo de fuego.

La misma reacción violenta con lo circundante es la que trajo el enorme cambio en la estructura de la sociedad europea y la ayudó a dar el salto cualitativo de la etapa de debilidad de la Edad Media a la etapa de fuerza del presente. La posición del gran erudito italiano Galileo frente a la autoridad central de la Iglesia tuvo una profunda influencia para liberar la mente europea de sus ataduras y lanzarla a una tremenda revolución intelectual, que fue el pilar básico para constituir el poder de la Europa moderna.

Los estudios filosóficos, sociales, económicos y psicológicos, que fueron el producto de esta revolución intelectual y trajeron consigo la posibilidad de aplicarla de forma práctica a través de la revolución industrial que surgió en Europa en ese momento, cambiaron muchos conceptos, relaciones y equilibrios.

Y no se trata de comprobar si estas ideas eran correctas o equivocadas, sino de demostrar que los grandes cambios que surgieron en Europa fueron el resultado de estos sacudidas intelectuales "revolucionarias", que luego se convirtieron en realidad sobre el terreno.

En nuestro mundo islámico actual, en lugar de tratar de crear un plan destacado que nos ayude a generar esas sacudidas que devuelvan la conciencia y que sean acordes con nuestra cultura, estamos tratando de reconciliar, de forma ingenua, lo que dijeron los sabios de Occidente y el punto de vista islámico [...] Así estamos creando una relación incorrecta - en su sentido matemático- entre un conjunto completo e interconectado (el sistema occidental) y un conjunto parcial y fragmentado (nuestra percepción del sistema islámico). Es muy natural que dentro de este conjunto completo se formen unos sistemas capaces de funcionar y producir - a pesar de sus defectos- debido a la disponibilidad de sus componentes. Mientras tanto, nosotros somos incapaces de crear un sistema funcional por carecer de muchos de esos 
elementos dentro nuestro conjunto fragmentado, a pesar de su validez.

Quienes toman las decisiones y los que están en el poder en la mayoría de los países musulmanes tienen una gran responsabilidad en la quiebra social, económica y política de la sociedad, pero esto no niega la negligencia de nuestros intelectuales en crear lo que llamamos sacudida psicológica en sus sociedades reales para que puedan recuperar la conciencia de una manera racional, alejada del sentimentalismo vacío y el impulso espontáneo.

Lo que más tememos para el pensamiento islámico moderno es que sea como el movimiento rotatorio, incapaz de realizar el movimiento vertical que quite la barrera que separa los restos de un mundo estático, donde las ideas están muertas, y un mundo en movimiento, consciente de su existencia y su papel en el campo de la batalla cultural .

Nuestro segundo artículo es "La sociedad útil: ignorancia y superficialidad" (Al-muytama al-mufid: garawa wa-satbiya), publicado el 29 de junio de 1992, donde decía:

Lo que más nos ha hecho sufrir ha sido la aparición del despotismo cultural y el dominio intelectual de un grupo que se hace llamar "la sociedad útil", que dice ser portador de la cultura "útil" y se ha convertido en el más influyente en la promulgación de leyes y en decidir sobre el país, por lo que las personas obtienen su legitimidad de su cultura "útil" y de su lenguaje "superior y civilizado".

Este grupo se ha convertido en un juez que clasifica a las personas en buenas y malas, y no le importa - para conservar sus intereses- que la sangre de los argelinos siga corriendo ni que el pueblo no agradezca más que la tristeza y las lágrimas. Hoy este grupo rechaza cualquier síntoma que llame a un diálogo constructivo que nos evite un montón de tragedias, y trata de imponer su visión autoritaria, basada en la difusión de la cultura de la europeización, y de golpear 
todo lo que esté ligado a lo que ama la mayoría del pueblo, a su cultura y a su lengua.

El concepto de lengua superior y de sociedad útil es un concepto superficial y estúpido que demuestra una mentalidad autoritaria y representa la más repugnante imagen del despotismo, la coerción y el abominable terrorismo intelectual.

Me llamó la atención un artículo que leí en el periódico italiano La Stampa, publicado el 11 de febrero 1992 y firmado por el periodista Igor Man. He aquí la traducción de algunos de sus párrafos: "Inmediatamente después de la sorprendente victoria en las elecciones municipales del Frente Islámico de Salvación el 12 de junio de 1990, me dijo el portavoz oficial del Frente, 'Abassi Madani, que no podemos cortar el cordón umbilical que nos une a Europa, de la que importamos casi todo, pero ustedes tienen la democracia y nosotros tenemos la ley que respeta a los demás más de lo que ustedes se figuran”.

Y sigue diciendo el periodista: "Así que, ¿por qué esta conmoción que ha afectado a Europa tras la aplastante victoria lograda por el Frente Islámico de Salvación el 26 de diciembre de 1991? Puede deberse a la ignorancia y al engaño, pues los aparatos de información de los países anglosajones (y franceses por nuestra causa) nos pintan un horrible escenario, con un régimen dominado por extremistas, terroristas y gentes sucias, y que el famoso cordón umbilical que une a Europa con la orilla meridional del Mediterráneo se cortará, privándonos de gas y petróleo, y que Argelia volverá a la Edad Media, y los argelinos "buenos" inundarán Europa huyendo del infierno". El periodista comenta todo esto diciendo que el engaño es que nos hacen creer, a nosotros los europeos, que nuestro estilo de vida, que gira en su mayor parte sobre la producción materialista, es el mejor de los mundos. Quizás tengamos derecho a rechazar el modo de vivir de los iraníes, por ejemplo, pero quien nos da derecho a rechazar esto son los propios iraníes. La verdadera ci- 
vilización de una nación se mide por su respeto a las culturas distintas a la suya, y no por el desprecio de las otras culturas, que es el hermano gemelo del racismo.

El autor del artículo es un producto de la civilización occidental y la cultura europea, y no es un extremista o un oscurantista. Entonces ¿no es asombroso que encontremos entre nosotros a algunos “¡Doctores!” que se apresuraron a emitir declaraciones advirtiendo de las llamadas a la reconciliación que empezaron a elevarse para salvarnos de una destrucción total, y vieron en estas buenas disposiciones un obstáculo para el proceso de cambio radical? Con esta grosera y descarada provocación tal vez están trabajando para empujarnos a una explosión terrible.

No estamos revelando un secreto si decimos que el valor de este microgrupo no está en su fuerza. Las elecciones han demostrado su verdadero peso, pero su fuerza deriva de ser una extensión de lo que llama el pensador francés Roger Garaudy el fundamentalismo europeo, y lo que llamó Igor Man, en el artículo que hemos mencionado, la ignorancia y el engaño.

Sin embargo, ¿interesa al propio Occidente esa "coerción" cultural para imponer su estilo de vida a otros pueblos?

Creo que intentar esa supremacía cultural es muy peligroso al llevar las semillas de una fuerte explosión de violencia que llegará, no sólo a la estructura de las sociedades vulnerables, sino que se extenderá también a las sociedades desarrolladas. Occidente, con esa táctica coactiva, intenta hacer de su cultura una cultura superlativa que rechaza tratar con otras culturas, respetarlas, y trabaja para borrarlas y aniquilarlas.

Tal vez esto explica las violentas explosiones que han sacudido recientemente muchos de los sistemas del mundo que trataron de eliminar una cultura para perpetuar la supremacía de la cultura del poder, y Occidente debe tener en cuenta la multitud de pobres que se involucrarán en su mo- 
delo social de manera espontánea para huir de la cultura del poder y el despotismo.

Puede parecer contradictorio que los pueblos sometidos a su autoridad se escapen de una cultura que es el producto de la cultura hacia la que huyen y que vean en ella más libertad y justicia, pues hemos visto cómo muchos de los que se oponen al poder en los países árabes e islámicos huyen a Europa, a pesar de que se oponían a la aplicación de sus normas en su país.

Pero eso no es nada extraño en la medida en que la cultura europea es una cultura popular en las naciones que la han producido, mientras es una cultura elitista en las naciones que la han importado meramente como un bien de consumo. Así, al tiempo que los demócratas de Occidente pudieron hacer participar a las diferentes clases populares en la máquina del poder y en la marcha de las instituciones del Estado, nosotros encontramos que “¿nuestros demócratas?" son las personas más alejadas del pueblo y las que más lo desprecian a él, a la cultura y a la lengua local. Una simple estadística nos demostrará, por ejemplo, que en Argelia no hablan correctamente la lengua francesa más de un 20\%, pero que es usada como una herramienta por la élite para conservar su dominio cultural, político y económico y para descartar a la mayoría del círculo del poder. Es un método de selección que crea una barrera psicológica para todo el que aspira a alcanzar un rango prohibido en la mayoría de los casos para la gente común, es decir, que crea la "sociedad útil” dueña del lenguaje civilizado. Todavía recuerdo el incidente que le ocurrió a un amigo mío de juventud, cuando prefirió retirarse antes de que le examinara el médico porque nuestro médico no hablaba bien la lengua de Voltaire. Y podemos imaginar la magnitud del asunto si en lugar de un médico hubiera sido el director de una institución, un fiscal o un juez de instrucción.

Esta cultura elitista se ha convertido en una cultura de consumo en lugar de ser una cultura de producción y creati- 
vidad, porque se ha convertido en un requisito para la pertenencia honorífica a un determinado grupo. Frente a esta marginación se produce una rebelión irracional y violenta contra la sociedad o, viceversa, un comportamiento dócil y obediente respeto al poder elitista y selectivo.

Como en los estudios económicos, tenemos que responder a tres preguntas básicas: qué producimos, cómo producimos y para quién producimos. Tenemos también que hacer las mismas preguntas en el ámbito cultural de cualquier cultura: qué cultura producimos, cómo la producimos y para quién la producimos. Es decir, tenemos que tomar en cuenta a estos consumidores - la mayoría de la población-, pues el Occidente que produjo su cultura especial no produjo esa cultura para estos consumidores, ni la produjo a su medida. Por ello será responsable de los choques violentos que conocerán el tercer mundo y la propia Europa debido al conflicto en curso entre la clase dominante, que consume la cultura occidental, su material y sus medios, y la clase popular, marginada del círculo de las decisiones y el gobierno, lo que puede causar un tenso conflicto cerca de las puertas de Occidente. Por tanto, Occidente no es inmune a lo que sucede a su alrededor, sino que se va a encontrar, como resultado de la emigración de los pueblos sometidos a su poder, tratando con elementos totalmente extraños a su modelo cultural, y tiene que imaginarse lo que puede ocurrir a causa de las grietas y las convulsiones en su propia sociedad.

Y finalmente en "La confianza... el pan... y las armas" ( $A l-$ tiqa... wa-l-jubz... wa-l-silab), publicado el 29 de julio-1992, decíamos:

Una vez Tsé Koug preguntó a su maestro Kunfu Chius gran sabio de China - sobre la base de un buen gobierno, y el sabio maestro le respondió: "El gobernante debe garantizar a sus súbditos tres cosas: pan suficiente para todas las personas, armas suficientes para garantizar la seguridad, y 
confianza suficiente entre el gobernante y sus súbditos". El discípulo le preguntó qué cosa podríamos sacrificar si nos pidieran que prescindiéramos de una de las tres cosas, y le respondió el maestro: "Las armas". El discípulo volvió a preguntar. "¿Y si tuviéramos que elegir prescindir de una de las dos cosas restantes?". Y el maestro dijo: "El pan, porque la muerte siempre acompaña al hombre en su historia, pero, si el pueblo pierde la confianza en sus gobernantes, el estado pierde todo su sentido".

Esta gran sabiduría se remonta a más de veinticuatro siglos atrás y, sin embargo, sigue siendo una de las teorías más profundas sobre el gobierno. Cualquier intento de rechazarla es rechazar el concepto del estado de derecho, prolongar nuestro sufrimiento y ahondar nuestras heridas. Los acontecimientos han demostrado que imponer la visión unilateral por medio de la represión, evidente o enmascarada, no puede evitar a las sociedades el fenómeno de las explosiones que destruyen sus estructuras, sacudiendo las bases, porque la parte inferior es frágil y débil, a pesar del cemento "armado" con que se alzó el edificio. Esta práctica puede llevarnos a un camino sin salida de consecuencias dramáticas, no sólo para nuestra situación social y nuestra seguridad interior, sino que afectaría incluso a nuestra seguridad exterior.

La gran esperanza es que esta revolución cimiente el proceso de refundación de la nación árabe sobre bases nuevas, superando el impasse histórico que ha sufrido y sigue sufriendo dentro del mundo moderno. 